\title{
Türkçeyi Yabancı Dil Olarak Öğrenenlere Yönelik Motivasyon Engelleri Ölçeği: Türkçeye Uyarlama Çalışması "
}

\author{
Hatice Altunkaya ${ }^{* *}$, Emrah Boylu ${ }^{* * *}$
}

Makale Geliş Tarihi: 21/01/2019

Makale Kabul Tarihi: 28/04/2020

DOI: $10.35675 /$ befdergi. 515725

$\ddot{O} z$

Bu çalışmanın amacl, Kikushi ve Sakai (2009) tarafindan İngilizce öğrenen Japon ögrencilerin motivasyon engellerini belirlemeye yönelik geliştirilen ölçeğin, yabancı dil olarak Türkçe ögrenenlere yönelik uyarlanması ve psikometrik özelliklerinin tespit edilmesidir. Araştırmanın çalışma grubunu, 2017-2018 eğitim-öğretim yılında İstanbul Aydın Üniversitesi Aydın TÖMER'de ögrrenim gören 237 ögrenci oluşturmuştur. Yapılan analizler neticesinde ölçeğe ait güvenirlik katsayısı 0,861 olarak bulunmuştur. Faktör analizi sonucunda değişkenler toplam açıllanan varyansı \%49.61 olan 4 faktör altında toplanmıştır. Bu faktörlere ilişkin güvenirlik katsayllarl siraslyla 0,77; 0, 74; 0,75; 0,72 olarak bulunmuştur. Bu bulgular ışı̆̆ında, Yabancı Dil Olarak Türkçe Öğrenenlere Yönelik Motivasyon Engelleri Ölçeği'nin yabancı dil olarak Türkçe öğretimi sahasında araştırmacilar ve öğreticiler tarafindan kullanılabilecek geçerli ve güvenilir bir ölçme aracı olduğu sonucuna varılmıştır.

Anahtar Kelimeler: Motivasyon, motivasyon engeli, ölçek uyarlama, yabancı dil olarak Türkçe

\section{Motivation Obstacles Survey for Learning Turkish as a Foreign Language: Study for Adaptation to Turkish}

\begin{abstract}
The aim of this study is to adapt the scale developed by Kikushi and Sakai (2009) to identify the motivation barriers of Japanese students who learn English, and to determine the psychometric properties of the scale. Research's study group consisted of 237 students enrolled in Aydin University TOMER in the academic year of 2017-2018. As result of the analyses conducted, scale reliability was deduced as Cronbach Alpha $=0.861$. As result of the factor analysis, variables were grouped under 4 factors with a total explained variance of $49.61 \%$. Cronbach Alpha values with respect to these factors were found as 0.77; 0.74; 0.75; and 0.72, respectively. In light of these findings, it was concluded that Motivation Obstacles Survey for
\end{abstract}

\footnotetext{
* Bu çalışma, 3-5 Mayıs 2018 tarihlerinde düzenlenen 1. Kaşgarlı Mahmud Yabancılara Türkçe Öğretimi Sempozyumu'nda sözlü bildiri olarak sunulmuştur.

** Aydın Adnan Menderes Üniversitesi Eğitim Fakültesi Türkçe Eğitimi Ana Bilim Dalı, Aydın, Türkiye, hatice.altunkaya@adu.edu.tr, ORCID: 0000-0003-4498-194X (D)

*** İstanbul Aydın Üniversitesi Eğitim Fakültesi Türkçe Eğitimi Ana Bilim Dalı, İstanbul, Türkiye, emrahboylu@aydin.edu.tr, ORCID: 0000-0001-9529-7369
}

Kaynak Gösterme: Altunkaya, H. \& Boylu, E. (2020). Türkçeyi yabancı dil olarak öğrenenlere yönelik motivasyon engelleri ölçeği: Türkçeye uyarlama çalışması. Bayburt Eğitim Fakültesi Dergisi, 15(29), 186203. https://doi.org/10.35675/befdergi.515725 
Learning Turkish as a Foreign Language is a valid and reliable scaling tool that could be used by researchers and teachers in the field of teaching Turkish as a foreign language.

Keywords: Motivation, motivation obstacle, scale adaptation, Turkish as a foreign language

\section{Giriş}

Yabancı dil öğrenimi, dünyadaki ekonomik, siyasi ve teknolojik gelişmelere bağlı olarak insanoğlunun temel ihtiyaçlarından biri hâline gelmiştir. Bu kapsamda Türkçe de özellikle 2000'li yıllardan itibaren yabancı dil olarak öğrenilen diller arasında önemli bir yer edinmiştir. Türkçeyi yabancı dil olarak öğrenenlerin sayısındaki artış, Türkçenin öğrenilme amaçlarını da farklılaştırmaktadır. İlgili alanda yapılan çalışmalara bakıldığında ( Çangal, 2013; Boylu \& Çangal, 2014; Başar \& Akbulut, 2016; Dursun, 2017; Sayar, 2019; İpek \& Çelik, 2019; Orhan, 2019) Türkçeyi yabanc1 dil olarak öğrenen Bosna Hersekli, İranlı, Gürcistanlı, Suriyeli, Cibutili, Polonyalı, İsveçli öğrencilerin dili öğrenme amaçlarının ve ihtiyaçlarının farklı olduğu görülmektedir. $\mathrm{Bu}$ amaç farklılı̆̆ı, öğrencilerin dil öğrenme süreçlerindeki motivasyon farklılıklarını da etkilemektedir. Örneğin Türkçeyi izlediği TV programlarını anlamak için öğrenen bir İranlı öğrenci ile eğitimine Türkiye'de devam etmek için Türkçe öğrenen veya Türkçe öğrendikten sonra bir Türk şirketinde çalışmak isteyen öğrencinin dili öğrenme amacındaki farklılık ilgili süreçteki motivasyonları üzerinde doğrudan etkili olacaktır. Tüm eğitim basamaklarında ve hayatın her alanında önemli bir konu olan motivasyon konusu, Türkçenin yabancı dil olarak öğreniminde de üzerinde önemle durulması gereken bir konudur. Çünkü Ergür (2002) motivasyon ve başarı kavramları arasında bir ilişki olduğunu ve bu ilişkinin ne yazık ki pek çok öğrenci için ters yönlü çalıştığını belirtir. Bu durumda motivasyon, bireyin herhangi bir iş karşısında istekli ya da isteksiz olma seviyesi ile ilgili bir kavramdır. Bireyin yapacağı iş hakkında neler hissettiği, nasıl hissettiği o işin başarı ile ya da başarısızlıkla sonuçlanması üzerine etkisi olan bir duygu durumudur. Bu tür istek, güdü gibi hisler bileşkesi ile motivasyon duygusu oluşur. Bir öğrencinin öğrenme için istek duyması, o isteği için harekete geçmesi yani güdülenmesi ve bütün bunları yaparken olumlu hisler içinde bulunması motivasyonunun yüksek olması ile ilintilidir. Literatürde motivasyon kelimesi "kişiyi ihtiyaçlarını karşılamak üzere davranışa yönlendiren içsel süreç” (Lussier,1996), "davranışın yönü ve büyüklüğü" (Keller, 1983), "öğrencilerin başarılı olmalarının önemli bir ögesi” (Freedman, 1997) ve "bireylere karşı nasıl davranıldığıyla ve bireylerin yaptıkları iş hakkında neler hissettikleriyle ilgili olma durumu” (Keenan, 1996), “okuldaki öğrenci davranışlarının yönünü, şiddetini, kararlılığını ve eğitim ortamlarında istenilen amaca ulaşmada hızı belirleyen en önemli güç kaynaklarından biri” (Akbaba, 2006) olarak farklı şekillerde tanımlanmaktadır. Tanımların ortak noktası doğrultusunda motivasyon, öğrencilerin eğitimlerinde kalıcı istendik davranışlar meydana getirilebilmeleri amacıyla öğrenecekleri konuya ilgi, istek duymaları, bu ilgi ve istek için harekete geçmeleri ve bu süreçleri duyuşsal bakımdan yönetecek kudrete sahip olmaları olarak tanımlanabilir. 
Eggen ve Kauchok (2001) öğrenci motivasyonunu artırmada öğrenen odaklı sınıf modeline göre öğrenme odaklı sınıfin kendini düzenleyici öğrenci, öğretmen karekteristiği, okul ve sınıf ortamı ve öğretimsel değişkenler (aktaran Akbaba, 2006, s. 346) olmak üzere dört ögesi olduğunu belirtmişlerdir. Bunlar:

1) Kendini Düzenleyici Öğrenci: Hedef belirler, hedeflerini ayarlar, biliş ötesini ve stratejileri kullanır.

2) Öğretmen Karakteristiği: Öğretmenin coşkulu ve istekli olması, öğrencilerin motivasyonunu ve beklentilerini artırır.

3) Okul ve Sınıf Ortamı: İyi bir öğrenme ortamı; heyecan verici, eğlendirici, teşvik edici, öğrenme firsatlarının tanındığı; bilgiye kolay ulaşma imkânlarının, denenmiş alıştırma ve problemlerin ve neyin nasıl yapılabileceğinin çoğu zaman birebir gösterilmesi yoluyla etkili bir şekilde sunulduğu yerdir. Sınıf ve okul değişkenleri öğrencinin motivasyonunun artırılması için öncelikle düzen ve güven verici olmalıdır. Öğrenci başarılı olduğu zaman tekrar başarılı olma olasılığı da $\operatorname{artar}$ (Çelik, 2003, s. 139'dan aktaran Akbaba, 2006, s. 346).

4) Öğretimsel Değişkenler: Öğrenci aktif olduğunda güdülenme yüksek olur. Karara katılım da öğrencilerin değer sistemlerine, zihinsel yapılarına ve motivasyonlarına olumlu yönde etki etmektedir (Baltaş, 2002, s. 171'den aktaran Akbaba, 2006, s. 346)

Dörnyei (2005) ikinci dil öğrenme konusunda "Motivasyonel Öz Sistem" konusunu kavramsallaştırmıştır. Ushioda (2011) bu modeli, geçmiş dil öğrenme motivasyonlarının temel yönleri hakkındaki araştırmaların kapsamlı bir sentezi ve Gardner'ın teorisinin doğal bir ilerlemesi olarak açıklamıştır. Dörnyei (2009) ikinci dil Motivasyonel Öz Sistem'in psikoloji ve ikinci dil öğrenimi alanlarındaki gelişmelerin etkilerinin bir bileşiminden doğduğunu ifade etmektedir. Dörnyei (2001), Budapeşte'de (Macaristan) İngilizce veya Almanca olarak eğitim gören kişilerle yaptığı 10-30 dakikalık mülakatlardan yararlanarak gerçekleştirdiği yayınlanmamış çalışmasına (1998) dayanarak, motivasyon engeli olarak aşağıdaki dokuz faktörü sunmuştur:

1. Öğretmenlerin kişilikleri, taahhütleri, yeterliliği, öğretim yöntemleri.

2. Yetersiz okul tesisleri (büyük sınıf boyutları, uygun olmayan sınıf düzeyi veya öğretmenlerin sık sık değiştirilmesi).

3. Başarısızlık ya da başarı eksikliğinden dolayı kendilerine olan güvenin azalması.

4. Öğrenilen yabancı dile karşı olumsuz tutum.

5. Yabancı dil çalışmasının zorunlu doğası.

6. Öğrencilerin öğrendiği başka bir yabancı dilin etkisi.

7. Öğrenilen yabancı dilin topluluğuna karşı olumsuz tutum.

8. Grup üyelerinin tutumları.

9. Sinıfta kullanılan ders kitapları. 
Dörnyei (2001) tarafindan sunulan dil öğrenmede motivasyonu engelleyen faktörlere bakıldığında; öğretmenden kaynaklı faktörler, öğrenme ortamından kaynaklı faktörler, öğrencilerin hisleri ile ilgili faktörler ve öğrenilen ortamın fiziki özelliklerine bağl1 faktörler ile ilişkili olduğu görülmektedir. Öğretenler ve öğrenenler üzerinde etkisi bulunan motivasyon ve akademik başarı arasında bulunan pozitif ilişki çeşitli araştırmalar tarafından (Liu \& Hou, 2018; Hidi, 2016; Froiland \& Oros, 2014; Aktan, 2012; Kable \& Glimcher, 2007; Vansteenkiste, Simons, Lens, Soenens \& Matos, 2005) doğrulanmıştır. Zhang (2007) motivasyonu en fazla engelleyen faktörün öğretmen yetersizliği olduğunu ifade etmiş ve bunu, öğretmenlerin öğrencilerine veya kursa ilgisizlikleri, kafa karıştırıcı ve sıkıcı dersler, başarısız testler ve aşırı bilgi yüklemesi olarak tanımlanabilecek bir dizi davranış kümesinin yansıması olarak tanımlamıştır.

Çeşitli çalışmalar neticesinde hedeflenen öğrenim düzeyine ulaşabilmek için önemli bir faktör olduğu tespit edilen motivasyon, yabancı dil olarak Türkçe öğretimi sahası için de önemli bir faktör olarak görülmelidir. Çünkü ana dili Türkçe olmayan bireylere; dinleme, konuşma, okuma ve yazma becerilerinden oluşan dil becerilerini kazandırma çalışmaları eğitimin hem bilişsel hem de duyuşsal yönlerini göz önünde bulundurmayı, öğretenlerin ve öğrenenlerin motivasyonlarını artırmayı gerekli kılmaktadır. Yabancı dil olarak Türkçe öğretimi sürecinde öğrencilerin motivasyon engelleri düzeylerini tespit etmek, bu sahada çalışan öğreticilere, öğrencilere ve programı hazırlayanlara faydalı olabilecektir.

Diğer yabancı dillerin öğretiminde olduğu gibi Türkçenin yabancı dil olarak öğretimi de Avrupa Ortak Öneriler Çerçeve Metni tarafindan belirlenen dil yeterlikleri esas alınarak yapılmaya çalışılmaktadır. Bu doğrultuda, tüm yabancı dil becerilerine ilişkin kazanımlar ortak olmakta ve öğretim sürecinde kullanılan çeşitli yöntem, teknik, strateji gibi faktörlerden farklı dillerin öğretiminde yararlanılmaktadır. Yabancı dil olarak İngilizce öğretimi sahası için Kikuchi \& Sakai (2007) tarafindan geliştirilen Motivasyon Engelleri Ölçeği, yabancı dil öğrenen herkesi ilgilendiren özellikler taşımaktadır. Ölçeğin alt boyutları ve maddeleri incelendiğinde öğretmenler, sınıf özellikleri, başarısızlık deneyimleri, sınıf çevresi, sınıf materyalleri ve ilgi eksikliği alt boyutlarının yabancı dil olarak Türkçe öğrenenler için de önemli ögeler olduğu dikkati çekmektedir.

\section{Araştırmanın Amacı}

Bu çalışmanın amacı, Kikuchi ve Sakai (2009) tarafından geliştirilen ve 35 maddeden oluşan beşli likert tipi Motivasyon Engelleri Ölçeği'ni İngilizce orijinalinden Türkçeyi yabancı dil olarak öğrenenlere yönelik uyarlamak ve psikometrik özelliklerini tespit etmektir. 


\section{Yöntem}

\section{Çalışma Grubu}

Türkçeyi Yabancı Dil Olarak Öğrenenlere Yönelik Motivasyon Engelleri Ölçeği’nin geçerlik ve güvenirlik çalışmaları 2017-2018 eğitim öğretim yılı bahar döneminde İstanbul Aydın Üniversitesi Türkçe Öğretimi Uygulama ve Araştırma Merkezinde (Aydın TÖMER) öğrenim gören öğrenciler ile yürütülmüştür. Çalışma grubunda 237 öğrenci yer almıştır.

Tablo 1.

Çalışma Grubuna Dâhil Olan Yabancı Öğrencilere İlişkin Bilgiler

$\begin{array}{ccc}\text { Yaş } & \mathrm{N} & \% \\ 15-20 & 175 & 73,8 \\ 20-25 & 34 & 14,3 \\ 25-30 & 16 & 6,8 \\ 30+ & 12 & 5,1 \\ \text { Toplam } & 237 & 100,0\end{array}$

Kur Seviyesi

A2

76

32,1

B1

111

46,8

B2

41

17,3

C1

9

3,8

Toplam

237

100,0

Cinsiyet

Kadın

142

60

Erkek

95

40

Toplam

237

100,0

\section{Veri Toplama Aracı}

Kikuchi \& Sakai (2009) tarafindan geliştirilen Motivasyon Engelleri Ölçeği'nin orijinal hâli, beşli likert tipi olup 35 maddeden oluşmaktadır. Ölçek Japonya'da yabancı dil olarak İngilizce öğrenenlere yönelik olarak geliştirilmiştir. Ölçek, sınıf özellikleri (1-6 ve 26), başarısızlık deneyimleri (7-9, 27 ve 30), sınıf çevresi (21-25, 28 ve 29), sınıf materyalleri (16-20 ve 35) ve ilgi eksikliği (31-34) olmak üzere önceki deneyimlerden elde edilen beş faktör üzerine kurulmuştur. Ölçek, "Aşağıdaki ifade sizin için motivasyon engeli faktörü olarak ne kadar doğru?" sorusu üzerine şekillenmiş ve ölçeğin yanıtlanması 1: Doğru değil; 2: Genellikle doğru değil; 3: Doğru da değil, yanlış da değil; 4: Biraz doğru; ve 5: Doğru şeklindeki seçeneklerin öğrenciler tarafindan seçilmesi ile sağlanmıştır.

Sakai \& Kikuchi (2009) ölçek geliştirme çalışmasında 35 madde olarak uyguladığ1 formda 8 maddeyi $(15,26,28,29,30,31,33,34)$ çıkartarak 27 madde üzerinden 5 
faktörlü bir yapı elde etmiştir. Sakai \& Kikuchi araştırmasını İngilizce öğrenen ana dili aynı, aynı kültür ve algılara sahip örneklem üzerinde çalışmıştır. Bu araştırmada ana dili farklı, farklı kültür ve farklı algılara sahip, farklı uyruğa sahip öğrenciler üzerinde yapıldığından ölçek uyarlama çalışmasında 35 madde üzerinden öncelikle güvenirlik, madde analizi, açıklayıcı (keşfedici) faktör analizi ve sonrasında doğrulayıcı faktör analizi uygulanmıştır.

\section{İşlem Basamakları}

Ölçeğin uyarlama çalışmalarına ölçek sahiplerinden Sakai'den izin alınarak başlanmıştır. Gerekli izin sonrasında orijinali İngilizce olan ölçeğin Türkçeye çeviri aşamasına geçilmiştir. Araştırmayı gerçekleştiren iki uzman öncelikle bireysel olarak çeviriyi yapmışlar ve sonrasında çevirileri karşılaştırarak sentezlemişler ve uzman görüşü almak amacıyla üstte İngilizce asl, altta Türkçe çevirisi olacak şekilde bir form hâlinde düzenlemişlerdir. Bu formlar, 2 Türkçe eğitimi, 2 İngilizce eğitimi alanında iki kadın ve iki erkekten oluşan uzman grubuna ve ayrıca yabancı dil olarak Türkçe öğreten 6 okutmana sunulmuş ve uygun, uygun değil, sizin görüşünüz şeklindeki form yoluyla uzmanların görüssleri alınmıştır. Alınan görüşler ve öneriler doğrultusunda gerekli düzeltmeler ve düzenlemeler yapılmış ve ölçeğin Türkçe formuna uygulama için hazır olan son şekli verilmiştir. Son şekli verilen formlar, İstanbul Aydın Üniversitesi Aydın TÖMER'de, gönüllülük esasına dayalı olarak uygulanmıştır.

\section{Verilerin istatistiksel analizi}

Araştırmada elde edilen veriler SPSS 22.0 ve AMOS programı kullanılarak analiz edilmiştir. Ölç̧ğin yapı geçerliliği açılayıcı faktör analizi ve doğrulayıcı faktör analizi ile test edilmiştir. Ölçeğin iç tutarlılığ Cronbach alfa ile madde analizleri madde toplam korelasyon değerleri ile ölçülmüsşür.

\section{Bulgular}

Sakai ve Kikuchi (2009) ölçek geliştirme çalışmasında 35 madde olarak uyguladığ formda 16 maddeyi $(2,5,6,9,15,20,25,26,28,29,30,31,32,33,34$ ve 35 .) çıkartarak 19 madde üzerinden 5 faktörlü bir yapı elde etmiştir. Sakai ve Kikuchi (2009) araştırmasını İngilizce öğrenen ana dili aynı, aynı kültür ve algılara sahip örneklem üzerinde gerçekleştirmiş̧ir. Bu araştırma, ana dili farklı, farklı kültür ve farklı algılara sahip, değiş̧ik uyruğa sahip öğrenciler üzerinde yapıldığından ölçek uyarlama çalışmasında 35 madde üzerinden öncelikle güvenirlik, madde analizi, açıklayıcı (keşfedici) faktör analizi ve sonrasında doğrulayıcı faktör analizi uygulanmıştır.

Ölçeğin genel güvenirliği alpha $=0.801$ olarak bulunmuştur. Madde toplam korelasyon değerleri incelendiğinde 13 madde $(1,7,8,9,11,16,17,20,21,26,27$, 30, 31 numaralı maddeler) ölçeğe katkısı düşük $(r<0,3)$ olduğundan çıkartılarak ölçeğin güvenirliği alpha $=0,861$ olarak bulunmuştur. 
Yapılan Barlett testi sonucunda $(p=0.000<0.05)$ faktör analizine alınan değişkenler arasında ilişkinin olduğu tespit edilmiştir. Yapılan test sonucunda $(\mathrm{KMO}=0.838>0,60)$ örnek büyüklüğünün faktör analizi uygulanması için yeterli olduğu tespit edilmiştir. Faktör analizi uygulamasında varimax yöntemi seçilerek faktörler arasındaki ilişkinin yapısının aynı kalması sağlanmıştır. Faktör analizi sonucunda değişkenler toplam açıklanan varyansı \%49.61 olan 4 faktör altında toplanmıştır. Ölçeğe ait oluşan açıklayıcı faktör yapısı aşağıda görülmektedir:

Tablo 2.

Motivasyon engelleri ölçeği faktör yaptsı

\begin{tabular}{|c|c|c|c|c|}
\hline Boyut & Madde & $\begin{array}{l}\text { Faktör } \\
\text { Yükü }\end{array}$ & $\begin{array}{c}\text { Açıklanan } \\
\text { Varyans }\end{array}$ & $\begin{array}{c}\text { Cronbach's } \\
\text { Alpha }\end{array}$ \\
\hline \multirow{17}{*}{$\begin{array}{l}\text { Öğrencilerin Hisleri } \\
\text { ile İlgili Engeller } \\
(\text { Özdeğer }=6.028)\end{array}$} & 33. Türkçeye ilgimi & 0,739 & \multirow[t]{17}{*}{13,599} & \multirow[t]{17}{*}{0,778} \\
\hline & kaybettim. & & & \\
\hline & 34. Türkçe konuşan & 0,721 & & \\
\hline & biri olma hedefimi & & & \\
\hline & kaybettim. & & & \\
\hline & 28. Sinif & 0,658 & & \\
\hline & arkadaşlarımı & & & \\
\hline & sevmedim. & & & \\
\hline & 32. Türkçe öğrenme & 0,608 & & \\
\hline & amacımı artık & & & \\
\hline & kaybettim. & & & \\
\hline & 29. Arkadaşlarım & 0,595 & & \\
\hline & Türkçeyi sevmedi. & & & \\
\hline & 35. Sinavlardaki & 0,562 & & \\
\hline & Türkçe sorularının & & & \\
\hline & açık ve net cevapları & & & \\
\hline & yoktu. & & & \\
\hline \multirow{13}{*}{$\begin{array}{l}\text { Yetersiz Materyal } \\
\text { Kullanımı } \\
(\text { Özdeğer=2.033) }\end{array}$} & 24. Derslerde dil & 0,741 & \multirow[t]{13}{*}{12,872} & \multirow[t]{13}{*}{0,743} \\
\hline & öğrenmemizi & & & \\
\hline & kolaylaştıracak araç & & & \\
\hline & gereçler & & & \\
\hline & kullanılmadı. & & & \\
\hline & 23. Derslerde & 0,630 & & \\
\hline & İnternet kullanılmadı. & & & \\
\hline & 25. Derslerde Cd ve & 0,605 & & \\
\hline & bant gibi işitsel & & & \\
\hline & materyal & & & \\
\hline & kullanılmadı. & & & \\
\hline & 22. Derslerde video & 0,604 & & \\
\hline & ve dvd gibi görsel & & & \\
\hline
\end{tabular}




\begin{tabular}{|c|c|c|c|c|}
\hline & materyal & & & \\
\hline & kullanılmadı. & & & \\
\hline & 18. Derslerde ele & 0,593 & & \\
\hline & cümleleri & & & \\
\hline & yorumlamak çok & & & \\
\hline & zordu. & & & \\
\hline & 19. Ders kitabından & 0,521 & & \\
\hline & ve ek kaynaklardan & & & \\
\hline & çok sayıda okuma & & & \\
\hline & ödevi verildi. & & & \\
\hline & 6. Öğretmenler sik & 0,425 & & \\
\hline & sık ders & & & \\
\hline & kitaplarındaki & & & \\
\hline & cümleleri ezberle & & & \\
\hline & diye zorladi. & & & \\
\hline İletişim Engelleri & 14. Öğretmenlerin & 0,752 & 11,759 & 0,751 \\
\hline (Özdeğer=1.623) & açıklamalarını & & & \\
\hline & $\begin{array}{l}\text { anlamak kolay } \\
\text { değildi. }\end{array}$ & & & \\
\hline & 12. Öğretmenler, & 0,740 & & \\
\hline & öğrencilerin & & & \\
\hline & yanlışlarıyla alay & & & \\
\hline & ettiler. & & & \\
\hline & 15. Öğretmenler & 0,641 & & \\
\hline & öğrencilere bağırıyor & & & \\
\hline & veya kızıyorlardı. & & & \\
\hline & 13. Öğretmenler tek & 0,635 & & \\
\hline & yönlü açıklamaları & & & \\
\hline & çok sık yapıyordu. & & & \\
\hline Öğretmenlerin & 3. Derslerin çoğunda & 0,802 & 11,380 & 0,729 \\
\hline Yetkinliği ve & dil bilgisi & & & \\
\hline Öğretme Stilleri & anlatıliyordu. & & & \\
\hline (Özdeğer=1.230) & 4. Derslerin çoğu kur & 0,781 & & \\
\hline & geçme sınavina & & & \\
\hline & yönelikti. & & & \\
\hline & 5. Benden Türkçeyi & 0,575 & & \\
\hline & dil bilgisi açısından & & & \\
\hline & doğru kullanmam & & & \\
\hline & (konuşmam ve & & & \\
\hline & yazmam) & & & \\
\hline & bekleniyordu. & & & \\
\hline
\end{tabular}




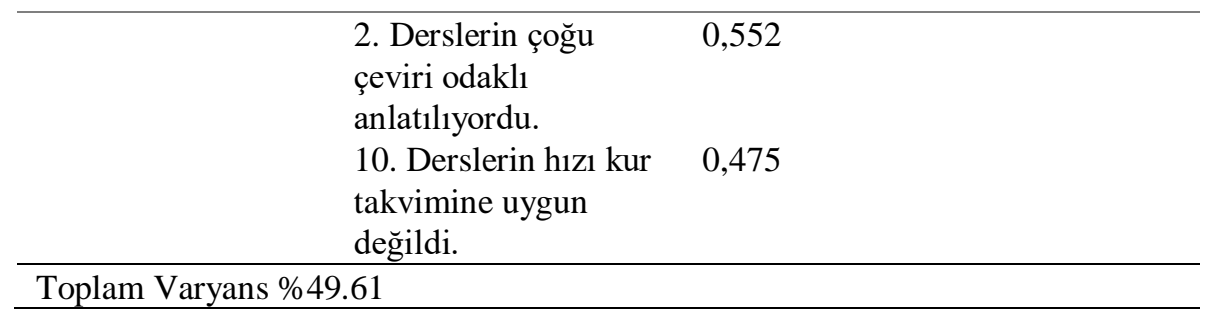

Açıklanan faktör analizi sonuçlarına göre faktör yapısının orijinal formdan farklı olduğu saptanmıştır. Açıklanan faktörlerin ifade edilen önermelerle örtüşmesi doğrulayıcı faktör analizi ile test edilmiştir. Çalışmada literatürde bulunan araştırmalarda en sık kullanılan uyum iyiliği indeksleri kullanılmıştır.

Tablo 3.

Motivasyon Engelleri Ölçeği Doğrulayıcı Faktör Analizi İndeks Dĕ̌gerleri

\begin{tabular}{lccc}
\hline İndeks & Normal Değer* & Kabul Edilebilir Değer* & $\begin{array}{c}\text { Motivasyon Engelleri } \\
\text { Ölçeği }\end{array}$ \\
\hline$\chi 2 /$ sd & $<2$ & $<5$ & 1.90 \\
GFI & $>0.95$ & $>0.90$ & .90 \\
AGFI & $>0.95$ & $>0.90$ & .90 \\
CFI & $>0.95$ & $>0.90$ & .90 \\
RMSEA & $<0.05$ & $<0.08$ &, 06 \\
RMR & $<0.05$ & $<0.08$ &, 07
\end{tabular}

*Kaynaklar: (Şimşek, 2007; Hooper \& Mullen 2008; Schumacker \& Lomax, 2010; Waltz, Strcikland \& Lenz 2010; Wang \& Wang, 2012; Sümer, 2000; Tabachnick \& Fidel, 2007).

Analiz sonuçları, doğrulayıcı faktör analizi ile hesaplanan uyum istatistiklerinin açıklanan faktörler ile uyumlu olduğunu göstermektedir. Doğrulayıcı faktör analizine ilişkin diyagram aşağıda verilmektedir: 


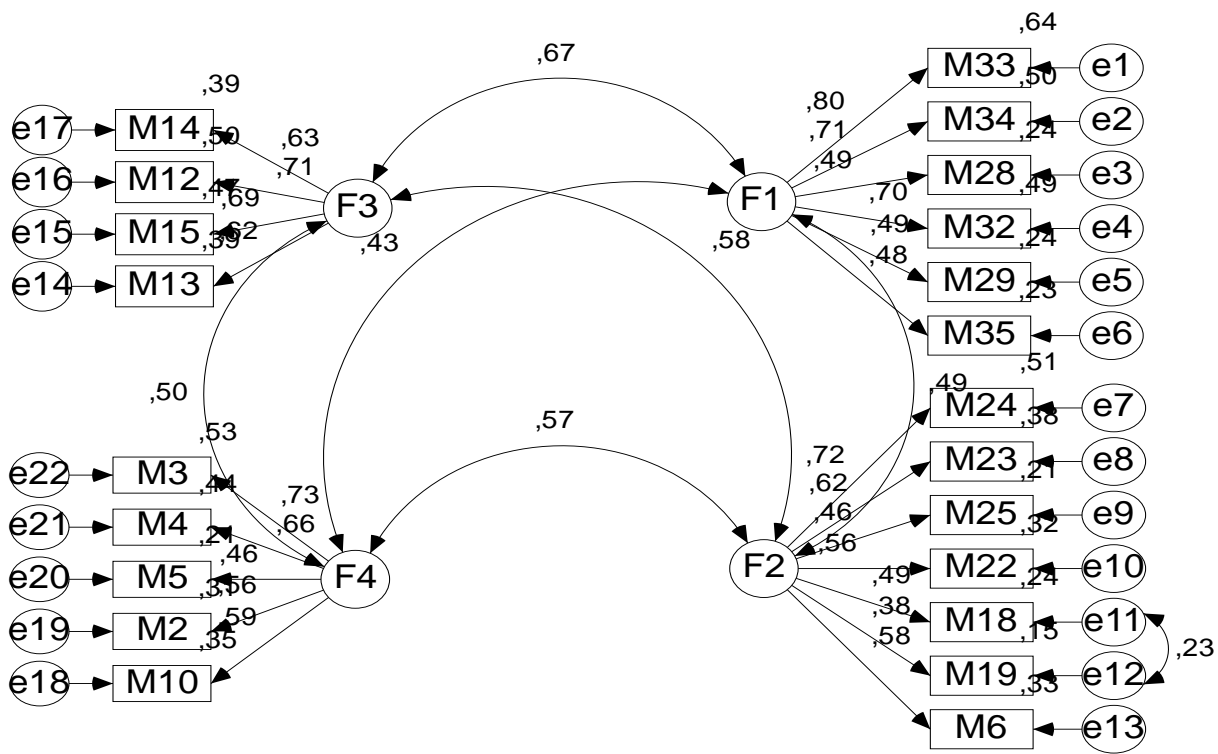

Şekil 1. Motivasyon engelleri ölçeği doğrulayıcı faktör analizine ilişkin diyagram

Doğrulayıcı faktör analizi sonrası modifikasyon indeks değerleri yüksek bulunan 18 ve 19 numaralı maddelerin hata terimleri arasında koveryans bağlantısı kurulmuştur. Standardize edilmiş faktör yükleri, t değerleri ve maddelerin oluşturduğu açıklayıcılık $\left(R^{2}\right)$ değerleri aşağıda verilmektedir.

Tablo 4.

Motivasyon Engelleri Ölçeği Faktör Yükleri Ve Maddelere İlişkin Regresyon Katsayılart

\begin{tabular}{lllrlllll}
\hline Maddeler & & Faktörler & $\beta$ & $\begin{array}{c}\text { Std. } \\
\beta\end{array}$ & S.Hata & t & $\mathrm{p}$ & $R^{2}$ \\
\hline M33 & $<---$ & F1 & 1 & 0,800 & & & & 0,534 \\
M34 & $<---$ & F1 & 0,943 & 0,709 & 0,090 & 10,492 & $\mathrm{p}<0,001$ & 0,439 \\
M28 & $<---$ & F1 & 0,670 & 0,494 & 0,093 & 7,171 & $\mathrm{p}<0,001$ & 0,485 \\
M32 & $<---$ & F1 & 0,900 & 0,703 & 0,087 & 10,401 & $\mathrm{p}<0,001$ & 0,413 \\
M29 & $<---$ & F1 & 0,624 & 0,490 & 0,088 & 7,099 & $\mathrm{p}<0,001$ & 0,438 \\
M35 & $<---$ & F1 & 0,725 & 0,485 & 0,103 & 7,023 & $\mathrm{p}<0,001$ & 0,574 \\
M24 & $<---$ & F2 & 1 & 0,717 & & & & 0,501 \\
M23 & $<---$ & F2 & 0,811 & 0,616 & 0,102 & 7,989 & $\mathrm{p}<0,001$ & 0,471 \\
M25 & $<---$ & F2 & 0,769 & 0,463 & 0,125 & 6,168 & $\mathrm{p}<0,001$ & 0,630 \\
\hline
\end{tabular}




\begin{tabular}{lllrlllll}
\hline M22 & $<---$ & F2 & 0,899 & 0,562 & 0,122 & 7,375 & $\mathrm{p}<0,001$ & 0,517 \\
M18 & $<---$ & F2 & 0,663 & 0,489 & 0,102 & 6,470 & $\mathrm{p}<0,001$ & 0,431 \\
M19 & $<---$ & F2 & 0,652 & 0,549 & 0,127 & 5,116 & $\mathrm{p}<0,001$ & 0,473 \\
M6 & $<---$ & F2 & 0,818 & 0,576 & 0,109 & 7,529 & $\mathrm{p}<0,001$ & 0,439 \\
M13 & $<---$ & F3 & 1 & 0,622 & & & & 0,477 \\
M15 & $<---$ & F3 & 0,927 & 0,686 & 0,117 & 7,936 & $\mathrm{p}<0,001$ & 0,496 \\
M12 & $<---$ & F3 & 1,021 & 0,708 & 0,126 & 8,090 & $\mathrm{p}<0,001$ & 0,514 \\
M14 & $<---$ & F3 & 0,980 & 0,628 & 0,131 & 7,475 & $\mathrm{p}<0,001$ & 0,543 \\
M10 & $<---$ & F4 & 1 & 0,590 & & & & 0,566 \\
M2 & $<---$ & F4 & 1,020 & 0,560 & 0,157 & 6,503 & $\mathrm{p}<0,001$ & 0,494 \\
M5 & $<---$ & F4 & 0,910 & 0,460 & 0,162 & 5,608 & $\mathrm{p}<0,001$ & 0,428 \\
M4 & $<---$ & F4 & 1,292 & 0,663 & 0,178 & 7,260 & $\mathrm{p}<0,001$ & 0,502 \\
M3 & $<---$ & F4 & 1,513 & 0,731 & 0,199 & 7,622 & $\mathrm{p}<0,001$ & 0,640 \\
\hline
\end{tabular}

Standardize edilmiş katsayılar incelendiğinde faktör yüklerinin yüksek, standart hata değerlerinin düşük, $\mathrm{t}$ değerlerinin anlaml $(\mathrm{p}<0,05), R^{2}$ değerlerinin yüksek olduğu belirlenmiştir. Faktörler arasındaki korelasyon katsayılarının 0.43-0.67 arasında değiştiği ve belirlenen faktörlerin birbirinden ayrı olduğu $(r<0.85)$ belirlenmiştir. $\mathrm{Bu}$ sonuçlar önceden belirlenen faktör yapısına ilişkin yapı geçerliliğini doğrulamaktadır.

\section{Yakınsama ve Ayırt Edicilik Geçerliği}

Yakınsama geçerliğinde 4 faktörün Ortalama Açıklanan Varyans (OAV) değerleri incelenmiştir. Ortalama Açılanan Varyans (OAV) değerleri F1: İlgi ve Odaklanmada Zorluk 27.4; F2: Yetersiz Materyal Kullanımı 9.2; F3: İletişim Engelleri 7.4; F4: Öğretmenlerin Yetkinlik ve Öğretme Stilleri 5.6 olarak bulunmuştur. Ölçeğin yakınsama geçerliğine sahip olduğu saptanmıştır.

Ayırt ediciliği belirlemek özere ölçek puanının alt \%27 ve üst $\% 27$ gruplar arasında $\mathrm{t}$-testi sonucuna göre anlamlı farklılık gösterdiği saptanmıştır $(\mathrm{t}=-28,020$; $\mathrm{p}=0,000<0,05)$. 
Tablo 5.

Ölçek Puan Ortalamaları Ve Korelasyon Değerleri

\begin{tabular}{|c|c|c|c|c|c|c|c|}
\hline & 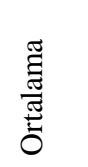 & 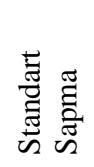 & 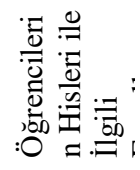 & 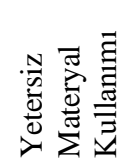 & 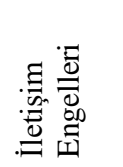 & 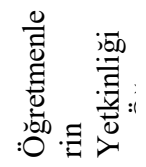 & 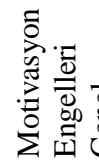 \\
\hline $\begin{array}{l}\text { Öğrencilerin Hisleri } \\
\text { ile İlgili Engeller }\end{array}$ & 1,603 & 0,746 & 1,000 & & & & \\
\hline $\begin{array}{l}\text { Yetersiz Materyal } \\
\text { Kullanımı }\end{array}$ & 1,969 & 0,841 & $0,364 * *$ & 1,000 & & & \\
\hline İletişim Engelleri & 1,650 & 0,828 & $0,525 * *$ & $0,428 * *$ & 1,000 & & \\
\hline $\begin{array}{l}\text { Öğretmenlerin } \\
\text { Yetkinliği ve }\end{array}$ & 2,594 & 1,043 & $0,337 * *$ & $0,446 * *$ & $0,395 * *$ & 1,000 & \\
\hline $\begin{array}{l}\text { Öğretme Stilleri } \\
\text { Motivasyon } \\
\text { Engelleri Genel }\end{array}$ & 1,953 & 0,645 & $0,713 * *$ & $0,794 * *$ & $0,722 * *$ & $0,752 * *$ & 1,000 \\
\hline
\end{tabular}

Yetersiz Materyal Kullanımı ve Öğrencilerin Hisleri ile İlgili Engeller arasında zaylf, pozitif yönde anlamlı ilişki bulunmaktadır $(r=0.364 ; \mathrm{p}=0,000<0.05)$. İletişim Engelleri ve Öğrencilerin Hisleri ile İlgili Engeller arasında orta, pozitif yönde anlamlı ilişki bulunmaktadır $(\mathrm{r}=0.525 ; \mathrm{p}=0,000<0.05)$. İletişim Engelleri ve Yetersiz Materyal Kullanımı arasında zayıf, pozitif yönde anlamlı ilişki bulunmaktadır $(r=0.428$; $p=0,000<0.05$ ). Öğretmenlerin Yetkinliği ve Öğretme Stilleri ve Öğrencilerin Hisleri ile İlgili Engeller arasında zayıf, pozitif yönde anlamlı ilişki bulunmaktadır ( $\mathrm{r}=0.337$; $\mathrm{p}=0,000<0.05$ ). Öğretmenlerin Yetkinliği ve Öğretme Stilleri ve Yetersiz Materyal Kullanımı arasında zayıf, pozitif yönde anlamlı ilişki bulunmaktadır ( $\mathrm{r}=0.446$; $\mathrm{p}=0,000<0.05$ ). Öğretmenlerin Yetkinliği ve Öğretme Stilleri ve İletişim Engelleri arasında zayıf, pozitif yönde anlamlı ilişki bulunmaktadır $(r=0.395 ; p=0,000<0.05)$. Motivasyon Engelleri Genel ve Öğrencilerin Hisleri ile İlgili Engeller arasında yüksek, pozitif yönde anlamlı ilişki bulunmaktadır $(r=0.713 ; p=0,000<0.05)$. Motivasyon Engelleri Genel ve Yetersiz Materyal Kullanımı arasında yüksek, pozitif yönde anlamlı ilişki bulunmaktadır $(r=0.794 ; \mathrm{p}=0,000<0.05)$. Motivasyon Engelleri Genel ve İletişim Engelleri arasında yüksek, pozitif yönde anlamlı ilişsi bulunmaktadır $\quad(\mathrm{r}=0.722 ; \quad \mathrm{p}=0,000<0.05)$. Motivasyon Engelleri Genel ve Öğretmenlerin Yetkinliği ve Öğretme Stilleri arasında yüksek, pozitif yönde anlamlı ilişki bulunmaktadır $(\mathrm{r}=0.752 ; \mathrm{p}=0,000<0.05)$.

\section{Ölçeğin Puanlaması}

Ölçeğin genel puanı ve alt faktörlerin puanları hesaplanırken maddelere verilen puanlar toplanarak madde sayısına bölünerek aritmetik ortalama hesaplanmaktadır. Genel puan ve alt faktörlerden elde edilen puanlar 1 ile 5 arasında değişmektedir. Ölçeğin genel puanı ve alt faktör puanlarının yükselmesi yabancı dil olarak Türkçe 
öğrenenlere yönelik motivasyon engellerinin yüksek algılandığını göstermektedir. Ölçekte ters madde bulunmamaktadır.

\section{Sonuç, Tartışma ve Öneriler}

Çalışmada, "Türkçeyi Yabancı Dil Olarak Öğrenenlere Yönelik Motivasyon Engelleri Ölçeği” Türkçeye uyarlanmış ve psikometrik özellikleri tespit edilmiştir. Senemoğlu (2007), motivasyonu yüksek olan öğrencinin öğrenmesinin üst düzeyde olduğunu; Ulusoy (2007) ise yeterince motive olmamış bir öğrencinin öğrenmeye hazır hâle gelmediğini ifade etmektedir. Dörnyei (2001) motivasyon engelini, davranışsal niyetin ya da devam eden eylemin motivasyonel temelini azaltan "özel dış güçler" olarak tanımlamaktadır. Sakai ve Kikuchi (2009), yabancı dil olarak İngilizce öğrenen Japon lise öğrencilerine yönelik gerçekleştirdiği çalışmalarında öğrenme içeriği, materyaller ve test sonuçları faktörlerinin özellikle motivasyonu düşük öğrenciler için motivasyon engeli olan faktörlerden olduğunu ifade etmişlerdir. Aynı çalışmada, öğretmen yeterliği ve öğretim stili faktörünün güçlü bir motivasyon engeli olmadığı, hem motivasyonu yüksek hem de düşük öğrencilerin yetersiz okul imkanlarının da motivasyon engeli olmadığı, motivasyonu düşük ve yüksek öğrencilerin motivasyonlarını engelleyen durumlara yönelik algılarının farklı olduğu belirtilmiştir. $\mathrm{Bu}$ bağlamda, eğitimin nihai hedeflerine ulaşmasında önemli bir etken olan motivasyonu engelleyen faktörlerin tespit edilmesinin önemli olduğu düşünülmüş ve yabancı dil olarak Türkçe öğretimi literatüründe böyle bir ölçek bulunmadığı görülmüştür. Bu çalışma ile bu eksikliğin giderilmesi, Türkçe öğrenen yabancıların motivasyonlarını engelleyen faktörlerin tespit edilmesi sağlanabilecek ve böylece motivasyonu engelleyen faktörlerin giderilmesi için çalışılarak eğitimin hedeflenen amacına ulaşmasına hizmet edilebilecektir.

Bu çalışmada, Türkçeye uyarlanan "Yabancı Dil Olarak Türkçe Öğrenenlere Yönelik Motivasyon Engelleri Ölçeği”nin geçerlik ve güvenirliğini destekleyen kanıtlar ifade edilmişsir.

Ölçeğin genel güvenirliği Cronbach Alfa $=0.801$ olarak bulunmuştur. Madde toplam korelasyon değerleri incelendiğinde 13 madde $(1,7,8,9,11,16,17,20,21$, $26,27,30,31$ numaralı maddeler) ölçeğe katkısı düşük $(\mathrm{r}<0,3)$ olduğundan çıkartılarak ölçeğin güvenirliği alpha $=0,861$ olarak bulunmuştur.

Yapılan Barlett testi sonucunda $(\mathrm{p}=0.000<0.05)$ faktör analizine alınan değişkenler arasında ilişkinin olduğu tespit edilmiştir. Yapılan test sonucunda $(\mathrm{KMO}=0.838>0,60)$ örnek büyüklüğünün faktör analizi uygulanması için yeterli olduğu tespit edilmiştir. Faktör analizi uygulamasında varimax yöntemi seçilerek faktörler arasındaki ilişkinin yapısının aynı kalması sağlanmıştır. Faktör analizi sonucunda değişkenler toplam açıklanan varyansı \%49.61 olan 4 faktör altında toplanmıştır. Bu faktörler, "Öğrencilerin Hisleri ile İlgili Engeller", "Yetersiz Materyal Kullanımı", İletişim Engelleri” ve "Öğretmenlerin Yetkinliği ve Öğretme Stilleri” olarak isimlendirilmiştir. Bu faktörlere ilişkin Cronbach Alfa değerleri 
sırasıyla 0,$77 ; 0,74 ; 0,75 ; 0,72$ olarak bulunmuştur. Yabancı Dil Olarak Türkçe Öğrenenlere Yönelik Motivasyon Engelleri Ölçeği’nin yabancı dil olarak Türkçe öğretimi sahasında araştırmacılar ve öğreticiler tarafından kullanılabilecek geçerli ve güvenilir bir ölçme aracı olduğu sonucuna varılmıştır. $\mathrm{Bu}$ sahada çalışan araştırmacılara ve öğreticilere Türkçe öğretim merkezlerindeki motivasyon engellerini tespit etmeleri için ölçeği kullanmaları önerilmektedir.

\section{Çıkar Çatışması ve Etik Bildirimi}

Yazarlar, aralarında çıkar çatışması bulunmadığını ve tüm araştırmacıların çalışmaya katkı sunduğunu beyan etmiştir. Yazarlar tüm etik kurallara uyduklarını bildirmiştir.

\section{Kaynakça}

Akbaba, S. (2006). Eğitimde motivasyon. Atatürk Üniversitesi Kazım Karabekir Eğitim Fakültesi Dergisi, 13, 343-361.

Aktan, S. (2012). Öğrencilerin akademik başarısı, özdüzenleme becerisi, motivasyonu ve ögretmenlerin ögretim stilleri arasında ilişki (Yayımlanmamış doktora tezi). Balıkesir, Balıkesir Üniversitesi Eğitim Bilimleri Enstitüsü.

Başar, U., \& Akbulut, E. (2016). Yabancılara Türkçe öğretiminde öğrenen ihtiyaçlarının belirlenmesi: Yunus Emre Enstitüsü Tiflis Türk kültür merkezi örneği. Uluslararası Türkçe Edebiyat Kültür Eğitim Dergisi, 5(2), 1005-1020.

Boylu, E., \& Çangal, Ö. (2014). Yabancılara Türkçe öğretiminde dil ihtiyaç analizi: İran örneği. International Journal of Language Academy, 2(4), 127-151.

Çangal, Ö. (2013). Yabancılara Türkçe öğretiminde dil ihtiyaç analizi: Bosna-Hersek örneği (Yayımlanmamış yüksek lisans tezi). Ankara, Gazi Üniversitesi Eğitim Bilimleri Enstitüsü.

Çelik, N., \& İpek, S. (2019). Yabancı dil olarak Türkçe öğretiminde dil ihtiyaç analizi: Polonya örneği. Aydın TÖMER Dil Dergisi, 4(2), 101-136.

Dörnyei, Z., (2001). Teaching and researching motivation. Longman, Harlow.

Dörnyei, Z. (2005). The psychology of the language learner: Individual differences in second language acquisition. Mahwah, N. J.: Lawrence Erlbaum.

Dörnyei, Z. (2009). The L2 motivational self system. In Z. Dörnyei, \& E. Ushioda (Eds.), Motivation, language identity and the L2 self (pp. 9-42). Clevedon, England: Multilingual Matters.

Dörnyei, Z. \& Ushioda, E. (2011). Teaching and researching motivation (2nd ed.). Harlow: Longman.

Dursun, H. (2017). Geçici koruma altındaki Suriyelilerin dil ihtiyaçlarının belirlenmesi: Şanlıurfa ili örneği (Yayımlanmamış yüksek lisans tezi). Adıyaman, Adıyaman Üniversitesi Sosyal Bilimler Enstitüsü. 
Ergür, D. O. (2002). Yabancı dil öğreniminde motivasyon kaynakları. Eğitim ve Bilim, 27(126), $38-42$.

Freedman, M. P. (1997). Relationship among laboratory instruction, attitude toward science, and achievement in science knowledge. Journal of Research in Science Teaching, 34(4), 343-357.

Froiland, J. M., \& Oros, E. (2014). Intrinsic motivation, perceived competence and classroom engagement as longitudinal predictors of adolescent reading achievement. Educational Psychology, 34(2), 119-132. doi: 10.1080/01443410.2013.822964.

Hidi, S. (2016). Revisiting the role of rewards in motivation and learning: Implications of neuroscientific research. Educational Psychology Review, 28(1), 61-93. doi: 10.1007/s10648-015- 9307-5.

Hooper D., Coughlan J., \& Mullen M. R. (2008). Structural equation modelling: Guidelines for determining model fit. Electronic Journal of Business Research Methods, 6(1), 53-60.

Hox, J. J., \& Bechger, T. M. (1998). An introduction to structural equation modeling. Family Science Review, (11), 354-373.

Kable, J. W., \& Glimcher, P. W. (2007). The neural correlates of subjective value during inter temporal choice. Nature Neuroscience, 10(12), 1625-1633. doi: 10.1038/nn2007.

Karasar, N. (2000). Bilimsel araştırma yöntemi (10. Baskı). Ankara: Nobel Yayınları.

Keenan, K. (1996.). Motivation. (E. KOPARAN., Çev.) İstanbul: Remzi Yayınevi.

Keller, J. M. (1983). Motivational design of instruction. C. M. Reigeluth (Ed.), Instructionaldesign theories and models: An overview of their current status (pp.383-434). Mahwah, NJ: Lawrence Erlbaum Associates.

Kikuchi, K., \& Sakai, H. (2009). Japanese learners' demotivation to study English: A survey study. JALT Journal, 31(2), 183-204.

Liu, Y., \& Hou, S. (2018). Potential reciprocal relationship between motivation and achievement: A longitudinal study, School Psychology International, 39(1), 38-55. sagepub.co.uk/journalsPermissions.nav doi: 10.1177/0143034317710574 journals.sagepub.com/home/spi

Lussier, R. N. (1996). Human relations in organizations: A skill-building approach. Boston: Irwin.

Mels, G. (2006). LISREL for Windows: Getting started guide. http://www.ssicentral.com/lisrel/techdocs/GSWLISREL.pdf

Orhan, D. (2019). Ísveç’te yabancı dil olarak Türkçe öğrenen yetişkinlerin dil ihtiyaçları analizi (Yayımlanmamış yüksek lisans tezi). Ankara, Başkent Üniversitesi Eğitim Bilimleri Enstitüsü. 
Sayar, E. (2019). Yabancı dil olarak Türkçe öğrenme nedenlerine yönelik bir ihtiyaç analizi: Cibuti örneği. Hacettepe Üniversitesi Yabancı Dil Olarak Türkçe Araştırmaları Dergisi, (5), 95-108.

Schumacker, R. E., \& Lomax R. G. (2004). A beginner's guide to structural equation modeling. New Jersey: Taylor \& Francis, 1-8.

Senemoğlu, N. (2007). Gelişim, öğrenme ve öğretim: Kuramdan uygulamaya. Ankara: Gönül Matbaacilik.

Sümer, N. (2000). Yapısal eşitlik modelleri. Türk Psikoloji Yazıları, 3(6), 49-74.

Şimşek Ö. F. (2007). Yapısal eşitlik modellemesine giriş, temel ilkeler ve LISREL uygulamaları. Ankara: Ekinoks Yayınları.

Tabachnick, B. G., \& Fidel, L. S. (2007). Using multivariate statistics. Pearson Education Inc. Boston. The academy of marketing science, 16(1), 74-94.

Ulusoy, A. (2007). Güdülenme. Ayten Ulusoy (Ed.), Eğitim Psikolojisi içinde (s. 307-325) Ankara: Anı yayıncılık.

Ushioda, E. (2011) Language learning motivation, self and identity: Current theoretical perspectives. Computer Assisted Language Learning, 24(3), 199210. DOI: $\underline{10.1080 / 09588221.2010 .538701}$

Vansteenkiste, M., Simons, J., Lens, W., Soenens, B., \& Matos, L. (2005). Examining the motivational impact of intrinsic versus extrinsic goal framing and autonomy - supportive versus internally controlling communication style on early adolescents' academic achievement. Child Development, 76(2), 483-501. doi: 10.1111/j.1467 8624.2005.00858.x.

Waltz, C. F., Strcikland, O. L., \& Lenz, E. R. (2010). Measurement in nursing and health research. New York: Springer Publishing Company; 176-8.

Wan, T. T. (2002). Evidence-based health care management: Multivariate modeling approaches. Springer: Netherlands.

Wang, J., \& Wang, X. (2012). Structural equation modeling: Applications using mplus: Methods and applications. West Susex: John Wiley \& Sons, 5-9.

Zhang, Q. (2007). Teacher misbehaviors as learning demotivators in college classrooms: A cross-cultural investigation in China, Germany, Japan, and the United States. Communication Education, 56, 209-227.

\section{Extended Abstract}

Since the purpose of learning Turkish as a foreign language differs for every individual who learns Turkish, this purpose difference also affects the motivation differences of students during the process of learning language. In this scope, when the importance of motivation is considered with respect to learning language, it could 
be said that there is a positive relation between achieving success and motivation in learning language. The word motivation is defined in the literature in different forms, some of which are "internal process that steers the individual to act for meeting one's needs" (Lussier, 1996), "direction and size of behaviour" (Keller, 1983), "an important element for students' success" (Freedman, 1997) and "state of being interested in how individuals are treated and how individuals feel about the work they do" (Keenan, 1996), "one of the most important power supplies in defining the direction, intensity, commitment of student behaviour in school and speed of reaching desired goals in an educational environment" (Akbaba, 2006).

Moving from the aforementioned definitions, motivation, which is identified as an important factor with respect to achieving targeted success in teaching and learning language, makes it a requirement to consider both the cognitive and affective aspects of linguistic skill development studies consisting of listening, speaking, reading and writing skills in teaching Turkish to those whose native language is not Turkish. Identifying what affects student motivation in teaching Turkish as a foreign language could be beneficial for teachers working in this field, students and program development processes.

The study was conducted using the scanning method (Karasar, 2000), a research approach that aims to describe a past or current state as is. In this regard, this study was conducted with the students enrolled in Istanbul Aydın University Turkish Teaching Center (TÖMER) in the spring term of the academic year of 2017-2018. 237 students took part in the study group. Adapted scale for the study was developed by Kikuchi \& Sakai (2009) for those learning English as a foreign language in Japan, which is a 5-point Likert scale consisting of 35 articles. The scale was established on six structures formed by previous experiences, which consists of class traits (articles 1-6 and 26), failure experiences (articles 7-9, 27 and 20), class surroundings (articles 21-25, 28 and 29), class materials (articles 16-20 and 35) and attention deficit (article 31-34). The scale, which is originally in English, was translated to Turkish. Two experts conducting the research first made the translation individually, and then merged them by comparing the translations; in order to receive expert opinion, they prepared these translations as a form, where the original English version was on top and the Turkish translation was at the bottom. These forms were submitted to a group of experts consisting of two women and two men, 2 of which was in the field of teaching Turkish and 2 was in teaching English, and 6 instructors teaching Turkish as a foreign language, and their opinions were collected with the form consisting of appropriate, not appropriate and your opinion titles. In light of the received opinions and suggestions, necessary corrections and arrangements were made and the Turkish version of the survey was finalized for application. Data collected in the study was analyzed using SPSS 22.0 and AMOS software. Scale's structure validity was tested with explanatory factor analysis and confirmatory factor analysis. Internal consistency of the scale was measured with Cronbach Alpha, and article analysis was measured with article total correlation values. 
Sakai \& Kikuchi (2009) formed a 5 -factor structure upon 19 articles by removing 16 articles $(2,5,6,9,15,20,25,26,28,29,30,31,32,33,34$ and 35) from the form, which was applied as 35 articles in the scale development study. Sakai \& Kikuchi conducted their research using an English learning sample group that has the same native tongue, same culture and same perception. As this research was conducted on students with different native tongues, cultures, perception and nationalities, first the reliability, article analysis, explanatory (exploratory) factor analysis, and later, confirmatory factor analysis was applied over 35 articles.

General reliability of the scale was found as Cronbach Alpha $=0.801$. When article total correlation values were examined, it was seen that 13 articles (articles 1, 7, 8, 9, $11,16,17,20,21,26,27,30,31)$ were found to have low contribution to the scale (r $<0.3$ ), hence were removed, which resulted in scale reliability to be Alpha $=0.861$.

As result of the Barlett test $(\mathrm{p}=0.000<0.05)$, it was identified that there is a relation between the variables included in the factor analysis. As result of the test, it was identified that sample size $(\mathrm{KMO}=0.838>0.60)$ was sufficient for factor analysis application. Varimax method was used in factor analysis, which provided for keeping the relation between the factors the same. As result of factor analysis, variables were grouped under 4 factors with a total explained variance of $49.61 \%$. These factors were named as "Obstacles About Students' Emotions", "Insufficient Use of Material", "Communication Obstacles" and "Competence and Teaching Skills of Teachers". Cronbach Alpha values with respect to these factors were found as 0.77; $0.74 ; 0.75$; and 0.72 , respectively. It was concluded that Motivation Obstacles Survey for Learning Turkish As A Foreign Language is a valid and reliable scaling tool that could be used by researchers and teachers in the field of teaching Turkish as a foreign language. Researchers and instructors working in this field are recommended to use this scale to identify motivation obstacles in Turkish teaching centers. 